\title{
Wine Intertwined with Education and Complexity Theory
}

\author{
GOKSENIN SEN \\ University of Victoria (Canada)
}

\section{Apéritif}

Do you like wine?

Yes, he said.

So do I... Especially red wine... Do you know how to make wine?

No.

Let me tell you a wine story...

It was a lovely August afternoon. The breeze carried the vibrant warmth of nature blended with the smell of the diverse colors of green, and it all felt like a big family gathering. The winery was located in a valley between a river and a backdrop of mountains. It was a perfect location for happy grapes because the mountains protected them like a father from the cruel North wind. The lively river was embracing the winery like a mother and providing essential humidity for grapes.

The owner of the winery was sitting under the huge oak tree where she could see the sunrays winking through the swaying leaves in the soft breeze. Despite the deck in front of the winery house she preferred to enjoy her wine under that huge oak tree, closer to her dear winery, in an old oak chair.

She had been making wine there for ten years. This was enough time for her to learn that the taste of the wine is not proportional to her expertise. She had one of her best wines in her second year and despite her increasing expertise she could not reach the same quality until the sixth year.

It was August and another harvest season was about to start. Like every year, it will be a surprise how this season's wine will taste. She could estimate what it would taste like but certainty does not match the essence of the winemaking journey. The climate treated the winery nicely over the last year. It had enough rain, soil and humidity from the river to support it well. The grapes looked happy. However, the relationship of all the variables in the winemaking process will determine the outcome; there was no guarantee that this year's grapes would turn out to be the best wine in ten years.

There are many other interrelated factors in winemaking besides the weather and soil. The time for harvest is also crucial because it determines the acid, sugar, and tannin 
of grapes. In the first fermentation, extra yeast is added according to the level of yeast in the grapes. The temperature is also crucial: for red wine it needs to ferment at $21-25^{\circ} \mathrm{C}$ and for white, $15-18^{\circ} \mathrm{C}$. Temperature consistency is also vital; any change in temperature may ruin the wine completely.

The second fermentation takes place in the barrel. The material and the age of the barrel play a major role in determining the taste of wine. The balance of malic and lactic acids should also be tested, since this balance affects the taste of the wine to a great extent. Bacteria culture is added to change the malic acid to lactic acid. If needed, sulfur tablets may help to correct the balance. During the second fermentation, the acidity and taste of the wine should be checked twice a month.

In the final filtration the dead yeast and other potential re-fermenting organisms should be clarified. There is no prescribed time to start the final filtration; it all depends on the uniquely evolving process.

If all these processes are done perfectly, there is no guarantee for a good wine. Anything can happen in the bottling process. Even the weather and humidity still affect this. Direct sunlight should be avoided since it changes the temperature and may cause pre-mature aging. Another factor to be avoided is movement, including the vibration of a refrigerator. Cork quality is another variable that affects the taste of wine. In order to prevent the interaction between air and wine, the cork should be kept moist, thus it is better to store the bottles horizontally. Another interdependent variable is the storing time. For white wine, storage should be about two years whereas red wine needs five to ten years.

In the same winery, with the same recipe, unique wines come into existence each year. There is no standard or certain outcome. Making wine is a uniquely complex phenomenon.

\section{Hors d'oeuvre}

The principal called all the Physics teachers to a meeting to inquire about the sudden decrease in the school's Physics achievement in the annual national standardized test. We ranked third among all the private schools last year and this year we ranked $15^{\text {th }}$. The principal wanted to find out how there could be such a difference between last year and this year. Nothing had changed. We had the same teachers, same curriculum, same texts, same school, and same organization. However, the result was very different.

It was like a courtroom atmosphere where he was questioning each Physics teacher. His intention was not to make us feel guilty; he really was surprised about the difference and wanted to learn the cause of this outcome. Still, he could not help being a questioning authority.

Each one of us tried to assure him that we did the very best we could. It was such an uncomfortable feeling. It was as if we did something wrong; however we were all confident that we did our best-no less than last year. He was not satisfied with our answers and it was disappointing. Instead of sitting on that leather chair with a guilty feeling having to defend my colleagues and myself and, I was imagining myself sitting in an oak chair in the shadow of a huge oak tree.

One of my life-long dreams has been to own a winery. I picture myself living there, reading my book in the shadow of my future oak tree enjoying my very own wine. I was ready to jump to that kind of life, but you never know what life brings you, and instead, I was here, sitting in a leather chair in a fancy meeting room, being questioned about my performance as a Physics teacher.

In my opinion, winemaking and teaching have many common fundamental characteristics. First, they both need tremendous effort, dedication and love. Second, they are both multi-layered open and living systems within which formulas and recipes work to a limited extent. Third, they both have components with an essence of 
interdependence and interaction, which creates a unique self-organization. Fourth, there is a complexity, which makes the outcome hard to explain.

That is why, when it was my turn I asked the principal whether he knew how to make wine. Then I told him about the complexity of wine making and all the relationships that affect the taste of wine at the end.

\section{Main Dish}

In a mechanical, machine-like system the whole is the sum of its parts, and can be separated into its parts. When the system is complete the parts coordinate with each other and the result of this coordination is certain and standard. For example, in a radio each part has its own function and the parts make the whole system work in a standard way. When a part is broken, it can be replaced with a new one and it will work again in the same way. Mechanical systems such as radios are called closed systems. Closed systems are descriptive, concrete, linear, and standard.

The winemaking example, however, is not a machine-like system. It is a system where the parts cannot be separated from the whole. The soil, the wine grapes, the weather, the variables during the process are all inseparable. We can carry and plant the same wine grapes to another place and apply the same process but then it will not be the same system anymore.

A winery is a unique system unto itself. The elements constituting the whole are interdependent and interconnected, thus we cannot completely formulate and be certain about the outcome. There is an ongoing continuous evolution, which intertwines with relationships and interactions. The winemaking is an open, complex system. Open systems are transformational, dissipative, self-organized, imbalanced complex systems. They have non-linear causal relationships and emerge from the evolution of feedback loops. Still, this multi-dimensional, arbitrary and dissipative essence leads to a sacred order - a pattern.

Different from the machine-like closed system there is no coordination between the parts in complex systems. Coordination is something the parts do in a closed system. However, in the winery example, the parts, as the constituents of an open system, do not do, they just be. This kind of being emerges from the relationships between the parts. Furthermore, the interrelated parts within the system evolve together.

The education system is not a machine-like system, rather it is a living, evolving, phenomenon, where each instant is unique, and thus it makes the whole process unique. Each instant is feedback for the next instant and change occurs non-linearly in multidimensional ways. In other words, the change within a system feeds itself; each feedback generates the next step, therefore it is an evolving process where the laws of linear prediction do not work.

There are also interdependent and interconnected variables in education. The curriculum, the school, the teachers, the texts may all be the same, but still the whole is a living and continuously evolving open system. We cannot formulate the education system in an encapsulated and isolated frame. Besides, we cannot isolate the learning experience from the ongoing life of the students. Seen this way, the earning phenomenon and the education system are living open systems.

Learning does not occur only in the class environment; it occurs during one's lifetime wherever the student happens to "be". As a unique complex system, a student's learning is affected by her parents, teachers, friends, environment, and her psychological moods, just to name a few. There are numerous factors that can affect a student's mood. For instance, commercials, movies, the content of his favorite television programs that year, computer games, the weather (the ratio of anions and cations in the air have a notable impact on human psychology), how much he does sports per week (the amount of endorphin and serotonin which are produced during physical activity has a great 
impact on how we feel), the developments in the country, or in the world, even by the things that he eats. There are tremendous amounts of variables, which belong to this uniquely complex learning phenomenon. However, a complex system does not emerge from one layer of variables; the variables have their own variables as well. For example, parents of a student are affected by their jobs, friends, and their financial and daily lives.

Learning is blended with continuously evolving phenomena, which cannot be expressed as a document and separated into its parts such as home, school, and the public life. Aoki's "lived curriculum" (1986) and Pinar's "currere" (1995,) are embedded in the essence of open complex systems. Despite learning phenomena being dynamic and complex, why do we still use curricula as closed and static systems?

I suggest that we should liberate the curriculum from tightly wrapped dusty closed files. It is a living and transformational phenomenon as described by its Latin etymologic roots currere. We cannot function in multi-dimensional open systems through the current linear, closed system recipes.

\section{Dessert}

After dinner, Port wine can be served as a dessert wine. Its sweet and delicious taste comes from intensely flavored grapes. It is fulfilled with the notes of caramel, cinnamon and vanilla.

The taste of wine is also transformational. The first sip gives the very best aroma of the wine, and the taste transforms after consuming to give a deeper essence. Wine tasting is a journey like capturing the essence of a sentence. The understanding transforms in time.

Dessert \#1: Complexity is not about objects, but about self-emergent inter-relations.

Dessert \#2: Complexity embeds a multi-dimensional simplicity.

Dessert \#3: Complexity theory in education is beyond horizons, which makes the invisible reachable.

As the soft breeze wafted through the branches, the owner of the winery thought to herself while sitting in her oak chair under the huge oak tree, "Like every other red wine, Port wine performs the best when it is aged and sits in wooden barrels, especially the oak ones."

\section{References}

Aoki, T. (1986/2005). Teaching as indwelling between two curriculum worlds. In W. Pinar, \& R. Irwin (Eds.), Curriculum in a new key: The collected works of Ted. T. Aoki. Mahweh, NJ: Erlbaum.

Pinar, W. (1995). Understanding curriculum: An introduction to the study of historical and contemporary discourses. New York: Lang.

Pinar, W. \& Irwin, R. (Eds.) (2005). Curriculum in a new key. Mahweh, NJ: Erlbaum.

About the Author:

Goksenin Sen is a doctoral student at the University of Victoria. She is a former physics teacher in her home country of Turkey. Her interest is in finding a relationship between quantum theory and complexity theory.

(c) Copyright 2012. The author, GOKSENIN SEN, assigns to the University of Alberta and other educational and non-profit institutions a non-exclusive license to use this document for personal use and in courses of instruction provided that the article is used in full and this copyright statement is reproduced. The author also grants a non-exclusive license to the University of Alberta to publish this document in full on the World Wide Web, and for the document to be published on mirrors on the World Wide Web. Any other usage is prohibited without the express permission of the author. 